\title{
OBSERVACIONES DEL GAMETOFITO DE THELYPTERIS RHACHIFLEXUOSA RIBA (THELYPTERIDACEAE)
}

\author{
Blanca Perez-Garcia \\ RAMON RIBA \\ Y \\ Aniceto Mendoza \\ Universidad Autónoma Metropolitana-Iztapalapa \\ Departamento de Biología \\ Apdo. Postal 55-535 \\ 09340 México, D. F.
}

\section{RESUMEN}

La germinación de las esporas y el desarrollo del gametofito laminar de Thelypteris rhachiflexuosa Riba siguen el patrón general mencionado en la bibliografía para otras especies del género; la germinación es del tipo Vittaria y el desarrollo laminar es del tipo Drynaria. Desde temprana edad se observan pelos unicelulares, cortos, capitados, glandulosos, tanto marginales como superficiales. La apertura de los anteridios se lleva a cabo por el desprendimiento de la célula opercular completa. Los arquegonios constan de cuatro hileras de células en el cuello y se observó uno con cinco hileras. Después de cien días del inicio de la germinación no se obtuvieron esporofitos.

\section{ABSTRACT}

Spore germination and the development of the mature prothallia of Thelypteris rhachiflexuosa Riba follow the general pattern described elsewhere for other species of the genus; the germination is of Vittaria-type and the development of prothallia is of Drynaria-type. There is an early differentiation of short unicellular glandular hairs on margins and surfaces of the lamina. The opening of the antheridia is accomplished by separation of the whole cap cell. Archegonia have a neck with four rows of cells and in one archegonium five rows instead of four were seen. No sporophytes were observed after 100 days in culture.

\section{INTRODUCCION}

La mayoría de los gametofitos de los helechos leptosporangiados son generalmente epigeos y de forma laminar-cordiforme o espatulada. En la familia Thelypteridaceae, la germinación de la espora y los gametofitos adultos son del tipo común de los helechos leptosporangiados y en distintas fases de su desarrollo forman pelos unicelulares o pluricelulares, simples o ramificados, aciculares o capitados, con secreción apical.

El género Thelypteris cuenta con cerca de 900 especies de distribución principal-mente tropical y subtropical y sus representantes americanos han sido estudiados taxonómicamente por Smith (1971), pero se conoce poco sobre el desarrollo de su fase gametofítica. 
Algunos trabajos previos, en su mayoría orientados al estudio de especies asiáticas, son los de Schmelzeisen (1933), Momose (1938), Kachroo (1963), Nayar y Chandra (1963), Atkinson y Stokey (1964), Huckaby y Raghavan (1981), Reyes Jaramillo y Pérez-García (1991) y Tigerschiöld (1989a, 1989b, 1990).

Thelypteris rhachiflexuosa Riba, pertenece al subgénero Goniopteris y se conoce solamente de la región de Los Tuxtlas, Veracruz, México. Tiene 3-6 pares de pinnas con margen entero a someramente lobado, mientras que $T$. oroniensis L. D. Gómez es endémico de Costa Rica y presenta un raquis flexuoso similar, 6-8 pares de pinnas y margen inciso 1/2-1/3 hacia la costa. La revisión de la literatura indica que aparentemente sólo ha sido estudiado el gametofito de una especie de este subgénero, Thelypteris biolleyi $(\mathrm{H}$. Christ) Proctor (Atkinson y Stokey, 1964).

\section{MATERIAL Y METODO}

Los ejemplares de T. rhachiflexuosa fueron recolectados en la Estación de Biología Tropical los Tuxtlas, Veracruz, México, (G. Ibarra Manrique s.n. abril 8, 1992; R. Riba 1683, UAMIZ) entre 250 - 350 m de elevación, en vegetación secundaria de selva alta perennifolia (Riba, 1989). Las esporas de esta especie se obtuvieron guardando segmentos fértiles con esporangios maduros y cerrados en sobres de papel, dejándolos secar a temperatura ambiente para propiciar la apertura de los esporangios por desecación en forma natural; el material así obtenido se tamizó con una malla Mont-Inox No. 200, abertura 0.074 mm, para eliminar fragmentos de esporangios y otras impurezas.

Se sembraron las esporas con una densidad media de 282 por $\mathrm{cm}^{2}$ en medio de Thompson con agar (Pérez-García y Riba, 1992) en cinco cajas de Petri, una de las cuales se cubrió con papel estaño para probar fotoblastismo. Los cultivos se sometieron a un régimen lumínico de $12 \times 12$ horas, con luz fría (Sylvania $75 \mathrm{~W}$ ), a una temperatura de $20-28^{\circ} \mathrm{C}$. Las cinco cajas se mantuvieron dentro de bolsas de polietileno transparente durante todo el proceso, abriéndose cuatro de ellas cada 8-10 días para definir el inicio de la germinación; en cada revisión se humedeció el medio con unas cuantas gotas de agua destilada previamente esterilizada, con objeto de evitar la desecación y de propiciar el desplazamiento de los anterozoides cuando los gametofitos alcanzaran la madurez sexual; la caja mantenida en la oscuridad, se abrió hasta los 100 días después de la siembra.

Las observaciones se hicieron en material vivo en las diversas fases de desarrollo y se usó Sudán III para detectar la presencia de grasas en los pelos de los gametofitos.

\section{RESULTADOS}

Las esporas de T. rhachiflexuosa son monoletes, elipsoidales con una perispora en forma de pliegues u olanes y miden $29 \times 42 \mu \mathrm{m}$.

La germinación se inicia a los 8 días, con la formación de una célula protálica y una rizoidal; la protálica se divide transversalmente formando un filamento de 2 a 4 células isodiamétricas (Figs. 1-2), aunque se observaron filamentos hasta de cuatro células alargadas, con los cloroplastos dispersos en el citoplasma, excepto en la célula terminal en la que se acumulan en el extremo distal. 
Pérez-García, et al.: Observaciones del Gametofito de Thelypteris rhachiflexuosa

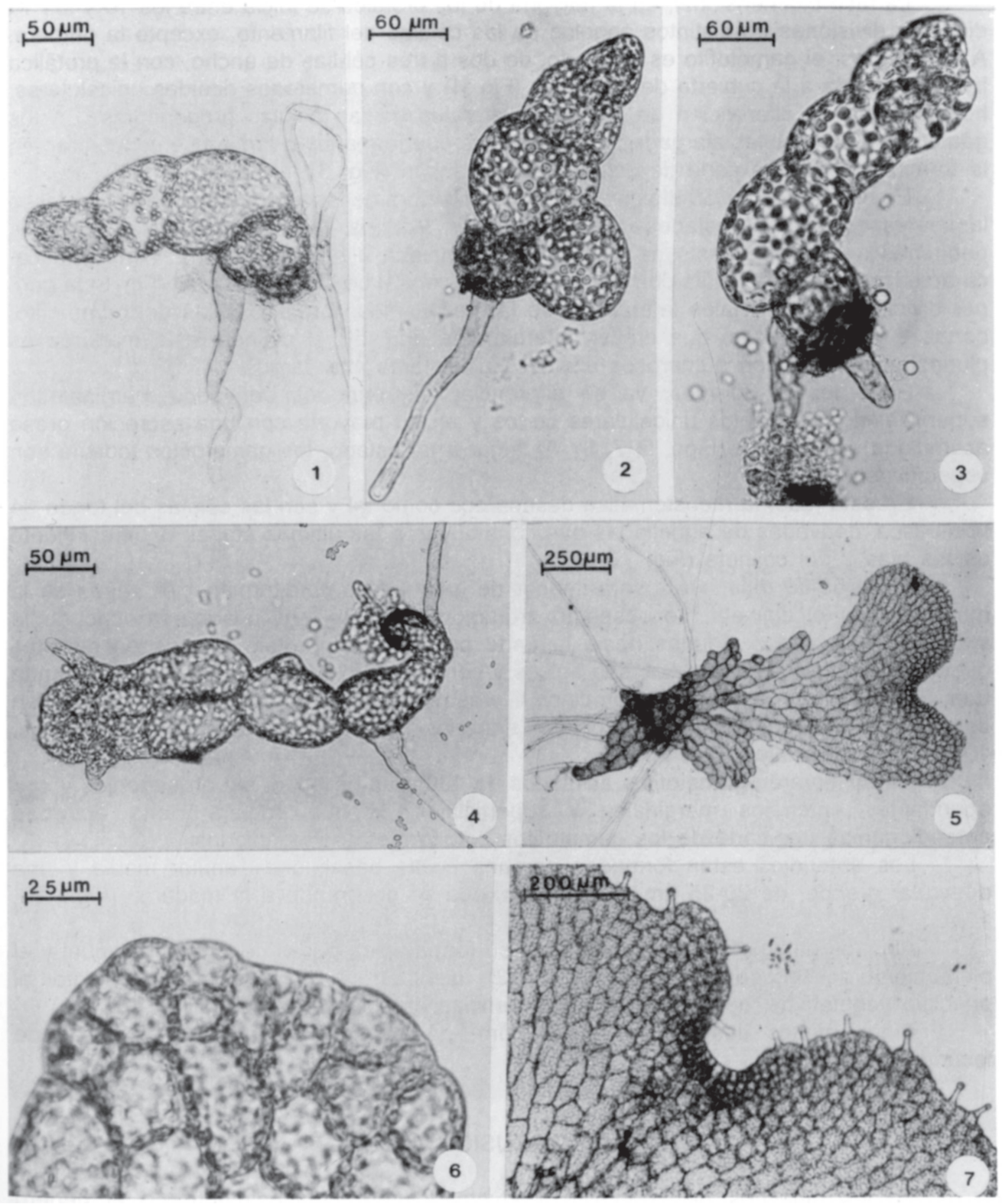

Figs. 1-7.- Morfogénesis del gametofito de Thelypteris rhachiflexuosa. 1-2. Fase unidimensional; 3-4. Inicio de la fase bidimensional; 5. Gametofito cordiforme joven y vegetativo; 6 . Inicio de la diferenciación de la zona meristemática; 7. Zona meristemática apical establecida. 
La fase bidimensional, en la mayoría de los protalos se inicia entre los 10 y los 14 días por divisiones en distintos ángulos de las células del filamento, excepto la primera. A los 20 días, el gametofito es alargado, de dos a tres células de ancho, con la protálica inicial adherida a la cubierta de la espora (Fig. 4) y con numerosos rizoides unicelulares, hialinos, que se diferencian de las caras laterales de las células progenitoras. En los gametofitos con células alargadas, las divisiones que formarán la lámina se concentran en la terminal como una serie de dos células de ancho (Fig. 3).

Entre los 25 y los 50 días después de la siembra de las esporas, se observan fases laminares en diversos estados de desarrollo, en algunos, las células distales son más pequeñas que las del resto del protalo y se empieza a perfilar la zona meristemática, caracterizada por una célula obcónica en la parte central de la región apical (Fig. 6) la que, por divisiones tangenciales laterales y de las resultantes, forma las alas del gametofito, cortas e isodiamétricas, que crecen lateralmente (Fig. 5); el cojinete a la madurez es pluriestratificado y con numerosos rizoides unicelulares muy largos.

Entre los 27-30 días, ya se diferencian los primeros derivados marginales y superficiales, como pelos unicelulares cortos y en su mayoría con una secreción grasa acumulada en la punta (Figs. 5, 7, 8). Al llegar a tal estado, los gametofitos todavía son vegetativos.

En esta fase, la meristemática desaparece como tal y son las células del fondo de la muesca, derivadas de aquella las que contribuyen a las últimas etapas del crecimiento de las alas y del cojinete (Fig. 7).

A los 55-60 días, en la cara inferior de gametofitos cordiformes, por detrás de la muesca y en el cojinete, se observan arquegonios con el cuello sobresaliendo de la superficie, orientados algunos hacia la parte posterior del protalo y otros en distintas direcciones (Fig. 9). Los cuellos son típicos y tienen cuatro hileras de 3 a 4 células cada una. Se observó un arquegonio con cinco hileras de células. Los anteridios se diferencian después de los arquegonios (proteroginia), entre los 100-130 días y son marginales (Figs. 10, 11) y superficiales (Fig. 8).

Se observaron gametofitos acintados de 130 días de edad, sin arquegonios y con abundantes anteridios marginales y superficiales, lo que sugiere cierta actividad anteridiogénica por parte de los gametofitos cordiformes arquegoniados.

Los anteridios están formados por una célula basal, una anular media y una opercular grande, de 20-25 $\mu \mathrm{m}$ de diámetro, que se desprende a la madurez (Figs. 10, 11).

Algunos gametofitos adultos pierden su forma típica por el desarrollo desigual y el plegamiento consecuente de las alas (Fig. 12), mientras que en otros hay crecimientos al principio vegetativos, pero después se diferencian anteridios y arquegonios (Fig. 13).

Cinco meses después de la siembra, no se han encontrado evidencias de fecundación.

\section{DISCUSION}

En los helechos de la familia Thelypteridaceae, principalmente en el género Thelypteris, se encuentra una notable uniformidad en la fase gametofítica, tanto en la germinación de la espora que es del tipo Vittaria (Nayar y Kaur, 1971) como en el desarrollo de la lámina protálica. En la germinación del tipo Vittaria la primera división de la espora 
Pérez-García, et al:: Observaciones del Gametofito de Thelypteris rhachiflexuosa
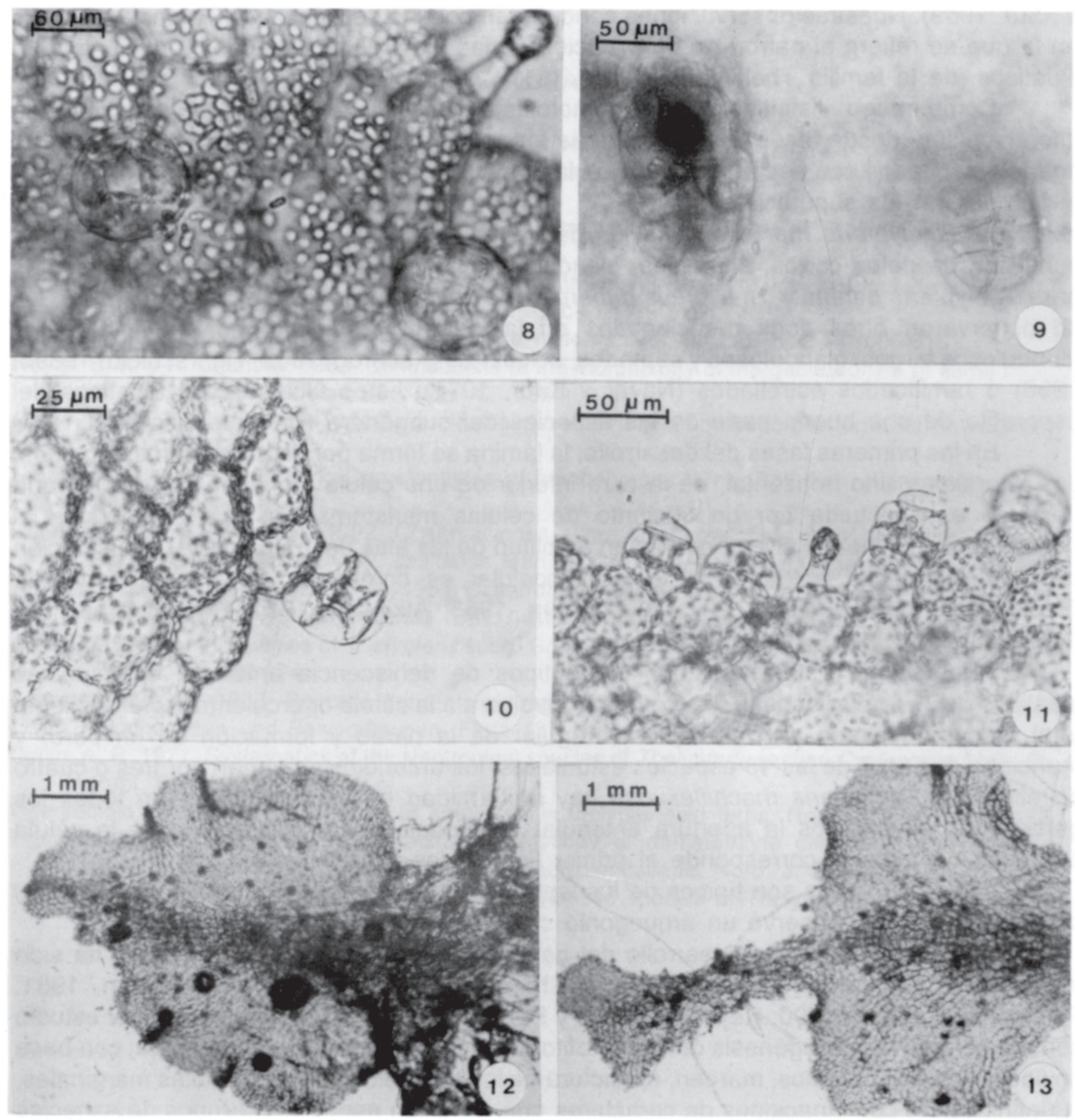

Figs. 8-13.- Morfogénesis del gametofito de Thelypteris rhachiflexuosa. 8. Anteridios superficiales y pelo glanduloso; 9. Arquegonios; 10-11. Anteridios marginales, se observan célula basal, célula anular y opérculo; 12-13. Gametofitos adultos maduros. En la Fig. 13 se destaca un crecimiento secundario apical. 
da lugar a dos células desiguales, una pequeña que de inmediato se alarga y diferencia en la primera rizoidal y otra más grande cuyas derivadas dan como resultado una lámina protálica, por lo regular cordiforme. Este desarrollo protálico es del tipo Drynaria (Nayar y Kaur, 1969). Nuestras observaciones concuerdan con las de Huckaby y Raghavan (1981) en lo que se refiere al patrón de germinación de las esporas de helechos, principalmente asiáticos, de la familia Thelypteridaceae.

Como rasgo distintivo de los gametofitos de Thelypteris se debe mencionar la diferenciación, desde fases tempranas de la formación de la lámina, de pelos unicelulares cortos y capitados con secreción grasa en la punta, primero en algunas células marginales y después en las superficiales.

En Thelypteris rhachiflexuosa los derivados marginales y superficiales solamente consisten de pelos cortos, capitados, glandulosos, unicelulares, similares a los descritos para Thelypteris patens y Thelypteris puberula (Reyes Jaramillo y Pérez-García, 1991). No se observaron otros tipos mencionados en la literatura revisada, por ejemplo, pelos glandulosos largos, glandulosos y septados, aciculares (Kachroo, 1963; Tigerschiöld, 1989b, 1990) o ramificados estrellados (Nayar y Kaur, 1971); estos últimos característicos del esporofito de una buena parte de las especies del subgénero Goniopteris.

En las primeras fases del desarrollo, la lámina se forma por divisiones en tres planos, dos laterales y uno horizontal, de la cara inferior de una célula meristemática inicial, que después es sustituida por un conjunto de células meristemáticas que contribuyen al desarrollo del cojinete y al crecimiento en amplitud de las alas del gametofito. La sustitución de la célula inicial por un meristemo pluricelular es común en otros subgéneros de Thelypteris (Kachroo, 1963; Nayar y Chandra, 1963; Atkinson, 1971; Reyes Jaramillo y Pérez-García, 1991).

Tigerschiöld (1989a) postula cuatro tipos de dehiscencia anteridial en especies asiáticas de Thelypteridaceae y en todos se involucra a la célula opercular (desprendimiento total, desprendimiento parcial, ruptura irregular de la pared y formación de un poro) y menciona que en 7 de las 18 especies estudiadas, los anteridios se abrían por tres o cuatro de ellos. En Thelypteris rhachiflexuosa hay uniformidad en este sentido y en todos los gametofitos observados la apertura anteridial se produjo por la separación de la célula opercular completa y corresponde al primer tipo de los citados.

Los arquegonios son típicos de los leptosporangiados, con cuatro hileras de cuatro células de alto. Se observó un arquegonio con cinco células apicales.

La uniformidad en el desarrollo del gametofito de especies de Thelypteris ha sido mencionada por varios autores (Nayar y Chandra, 1963; Huckaby y Raghavan, 1981; Tigerschiöld, 1989b, 1990; Reyes Jaramillo y Pérez-García, 1991). Sin embargo, el estudio comparativo de la morfogénesis del gametofito en especies americanas, permitirá, con base en tipo y posición de pelos, margen, estructura de los anteridios y tipo de células marginales, la definición de combinaciones de caracteres que delimiten especies o grupos de especies de Thelypteris (Tigerschiöld, 1989b).

\section{AGRADECIMIENTOS}

Los autores agradecen a los revisores anónimos y al Dr. Luis Diego Gómez Pignataro la revisión y las valiosas sugerencias al manuscrito y a los encargados de los herbarios 
Pérez-García, et al.: Observaciones del Gametofito de Thelypteris rhachiflexuosa

MEXU y MO, las facilidades brindadas para la consulta de las colecciones. Se reconoce cumplidamente el apoyo brindado por Guillermo Ibarra M., durante el trabajo de campo en Los Tuxtlas.

\section{LITERATURA CITADA}

Atkinson, L. R. 1971. The gametophyte of Thelypteris erubescens. Amer. Fern J. 61: 183-186.

Atkinson, L. R. y A. G. Stokey. 1964. Comparative morphology of the gametophyte of homosporous ferns. Phytomorphology 14: 51-70.

Huckaby, C. S. y V. Raghavan. 1981. The spore-germination on patterns of Thelypteroid ferns. Amer. J. Bot. 68: 517-523.

Kachroo, P. 1963. Observations on certain aspects of the development of the gametophyte of Cyclosorus molliuscula (Wall.) Ching. J. Indian Bot. Soc. 42: 190-194.

Momose, S. 1938. Studies on the gametophyte of ferns. VIII. J. Jap. Bot. 14: 606-616.

Nayar, B. K. y P. Chandra. 1963. Contributions to the morphology of the gametophyte of some species of Cyclosorus. J. Indian Bot. Soc. 42: 392-400.

Nayar, B. K. y S. Kaur. 1969. Types of prothallial development in homosporous ferns. Phytomorphology 19: $179-188$.

Nayar, B. K. y S. Kaur. 1971. Gametophytes of homosporous ferns. Bot. Rev. (Lancaster) 37: 350351.

Pérez-García, B. y R. Riba. 1992. Observaciones sobre los gametofitos de Woodwardia martinezii Maxon ex Weatherby y W. spinulosa Mart. \& Gal. (Blechnaceae). Acta Bot. Mex. 21: 7-14.

Reyes Jaramillo, I. y B. Pérez-García. 1991. Desarrollo de los gametofitos de Thelypteris patens (Swartz) Small y de Thelypteris puberula (Baker) Morton var. puberula. Acta Bot. Mex. 16: 7-13.

Riba, R. 1989. A new species of Thelypteris subg. Goniopteris from the state of Veracruz, Mexico. Amer. Fern J. 79: 122-124.

Schmelzeisen, W. 1933. Beiträge zur Entwicklungsgeschichte der Prothallien einiger Marattiaceen, Cyatheaceen und Polypodiaceen. Flora 127: 46-80.

Smith, A. R. 1971. Systematics of the Neotropical species of Thelypteris section Cyclosorus. Univ. Calif. Publ. Bot. 59: i-vi, 136, 5 pl.

Tigerschiöld, E. 1989a. Dehiscence of antheridia in thelypteridoid ferns. Nord. J. Bot. 9: 407-412.

Tigerschiöld, E. 1989b. Scanning electron microscopy of gametophyte characters and antheridial opening in some Ceylonese species of Thelypteridaceae. Nord. J. Bot. 8: 639-648.

Tigerschiöld, E. 1990. Gametophytes of some Ceylonese species of Thelypteridaceae. Nord. J. Bot. 9: $657-664$. 